\title{
As Interações Professor-Professor na Co-Construção dos Projetos Pedagógicos na Escola
}

\author{
Mírian Raposo ${ }^{1}$ \\ Diva Albuquerque Maciel \\ Universidade de Brasília
}

\begin{abstract}
RESUMO - A qualidade das interações entre professores é uma realidade da cultura escolar de fundamental importância para o desenvolvimento do seu projeto pedagógico e do currículo vivido pelo aluno. Arquitetado nos pressupostos teóricos da abordagem sociocultural construtivista, este trabalho teve como objetivo investigar os processos co-construtivos presentes nas interações professor-professor, fundamentais para a elaboração e execução dos projetos vividos em uma escola pública de formação de professores do Distrito Federal. Participaram do estudo os 23 professores do curso normal, a coordenadora e o diretor. Procedimentos de observação participante das atividades pedagógicas de planejamento e execução de projetos e entrevista semi-estruturada com 10 desses participantes foram realizados em um período de três meses. A análise dos resultados focalizou (1) relações de confiança (2) interdependência indivíduo-grupo e (3) liderança. Estas categorias foram cruciais para o alcance dos objetivos estabelecidos na escola. Considera-se que estas são contribuições importantes da Psicologia aos cursos de formação inicial e continuada de professores.
\end{abstract}

Palavras-chave: interação professor-professor; co-construção dos projetos pedagógicos; formação de professores.

\section{The Teacher-Teacher Interactions in the Co-Construction of Pedagogical Projects within the School}

\begin{abstract}
The observation of specific difficulties that are harmful to the accomplishment of pedagogical goals is always present in educational settings. This study is based on theoretical assumptions, which are peculiar to the socio-cultural constructivist approach. The objective was to investigate the co-constructive processes in the interactions between teachers, which are fundamental to the elaboration and execution of educational projects in a public school of the Federal District. Twenty-three teachers, the coordinator of the regular course and the principal took part in the study. Participative observable procedures were used in the analysis of the pedagogical activities that were accomplished during the planning and execution of educacional projects. Semistructured interviews were used for a three-month period. The analysis of the findings focused on (1) relationships of trust (2) interdependence individual-group and (3) leadership, which proved to be crucial factors to accomplish the common goals established. These are important inputs from Psychology to the primary and ongoing teacher's training programs.
\end{abstract}

Key words: interaction teacher-teacher; co-building of pedagogical projects; teacher education.

A partir da década de 50 do século passado, os estudos que envolvem a questão escolar têm, de forma crescente, apontado a importância das interações interpessoais para o desenvolvimento e aprendizagem do aluno. A maior parte desses estudos tem enfatizado principalmente a relação professor-aluno e, em menor grau, mas também de forma significativa, a relação entre pares (Branco, 1998; Maciel, 1996, 1999; Salomão, 2001; Tacca, 2000). Entretanto, pouco se tem estudado sobre a interação entre professores. A esse respeito, quem está imerso no dia-a-dia da escola sabe que a qualidade dessas interações é fundamental para o desenvolvimento do projeto pedagógico e, portanto, das condições curriculares vividas de fato pelo aluno.

A dificuldade nas interações entre os professores é uma realidade da cultura escolar observada mesmo entre professores da mesma área e da mesma série. Tal realidade implica, em geral, em resultados educacionais que ficam muito aquém

1 Endereço: SHIGS 707 Bloco B casa 28, Brasília, DF, Brasil 70351-702. E-mail:rmirian@unb.br do seu potencial de realização. Por outro lado, observamos que, nas escolas onde se consegue co-construir um bom nível de interações sociais, constata-se a potencialização dos resultados educacionais e do desenvolvimento dos trabalhos, tanto individuais quanto coletivos.

Arquitetado nos pressupostos teóricos da abordagem sociocultural construtivista, este trabalho teve como objetivo: identificar os processos co-construtivos de elaboração, planejamento, execução e avaliação dos projetos vividos no interior de uma escola pública de formação de professores, situada no Distrito Federal. Interessou-nos, especificamente, investigar os processos interativos presentes nessa situação de grupo, que são fundamentais para a realização dos objetivos construídos na proposta pedagógica e nos projetos individuais e coletivos.

\section{A abordagem sociocultural construtivista e as interações sociais}

A abordagem sociocultural construtivista constitui-se numa perspectiva teórica que abrange conceitos de várias 
correntes de pensamento, desde James Baldwin e Kurt Lewin até as atuais abordagens construtivistas e sócio-históricas. Tem como pressupostos básicos a noção de gênese social dos processos psicológicos superiores e a participação ativa do sujeito na produção do seu processo de desenvolvimento. Por outras palavras, o desenvolvimento humano ocorre através da interação dialética entre processos de canalização cultural e de constituição do indivíduo, enquanto sujeito ativo e coparticipante do seu próprio desenvolvimento.

Nessa perspectiva, a natureza social da personalidade humana emerge no curso de dois processos: a internalização dos processos sociais externos e a externalização de fenômenos psicológicos internos. Estes conduzem à construção da cultura pessoal guiada - mas não determinada - pela cultura coletiva. Da mesma forma, a cultura coletiva não é estática e seu desenvolvimento pode ser parcialmente influenciado pelas culturas pessoais. Tais processos, que são aspectos inseparáveis de um mesmo fenômeno, preservam o papel ativo da pessoa, ao mesmo tempo em que vinculam a este a orientação para objetivos (goal orientations) de "outros sociais" que a alimentam com sugestões sociais (Branco \& Valsiner, 1997; Valsiner, 1997).

É, portanto, uma perspectiva bidirecional de transmissão cultural, no sentido em que permite que se tome a cultura simultaneamente ao nível da unidade social ou coletiva e ao nível da pessoa. Isto é, cada pessoa elabora dentro de si a versão internalizada, portanto própria, da cultura coletiva. Esta noção de transmissão cultural bidirecional é de fundamental importância para a perspectiva teórica (ver, por exemplo, Maciel, Branco \& Valsiner, 2004; Valsiner, 1997) na medida em que indica processos por meio dos quais é possível pensar tanto a construção do novo quanto a singularidade do indivíduo. Além disso, cultura aqui é vista como um produto da construção semiótica. Esta, por sua vez, é sempre influenciada pela sugestão social. Dessa forma, é através da ação conjunta das sugestões sociais e da participação ativa do sujeito no desenvolvimento de simbolizações personalísticas do objeto que o ser humano participa de seu desenvolvimento. Cultura, quando vista desta perspectiva, é entendida como uma forma organizacional dinâmica de interações pessoais e de processos intra-mentais.

Esse movimento dialético pode ser detectado dentro do fluxo de negociações de cada objetivo particular do indivíduo com seu grupo. Para estudar os processos interativos que ocorrem entre os membros de uma escola, portanto, é imprescindível levar em conta, tanto os aspectos mais amplos, sociais e institucionais, como também os aspectos referentes aos seus significados, valores, regras e expectativas, que estão, a cada instante, sendo negociados no seu interior.

\section{Interações professor-professor e projeto político- pedagógico}

Estudos sobre a importância das interações entre professores para o seu próprio desenvolvimento e para o desenvolvimento do projeto político-pedagógico da escola são escassos. Pensar essas interações segundo a perspectiva sociocultural construtivista, significa considerar a construção de conhecimentos por uma pessoa participante ativa das sugestões culturais coletivas, o que implica uma forma dinâmica de processo de negociação de objetivos dos diferentes indivíduos em interação. $\mathrm{O}$ processo de negociação de objetivos faz emergir, segundo Branco e Mettel (1995), as noções de convergência e divergência. Na convergência de objetivos, observa-se a existência de compatibilidade entre os objetivos dos indivíduos em interação, o que poderá conduzir o grupo a um processo de cooperação que o leve aos fins desejados.

Na divergência, os objetivos de cada uma das partes no processo interativo são incompatíveis. De acordo com essa perspectiva, em contextos de interação social, divergências podem representar um movimento que favorece a emergência de novos elementos de informação e, conseqüentemente, podem conduzir a uma atividade reconstrutiva que resulta em novos padrões de interação. O movimento de divergência para convergência, muito freqüentemente observado em processos interativos, conduz à ocorrência de processos de negociação, através dos quais, conflitos de objetivos podem ser coordenados para possibilitar o surgimento da compatibilidade e, conseqüentemente, ao alcance dos objetivos coletivamente estabelecidos (Branco \& Valsiner, 1994).

Alguns estudos sobre interação (Branco \& Valsiner, 1997; Piaget, 1966; Valsiner, 1987/1997; Wallon, 1971) deixam claro que a cooperação intelectual em torno de um problema comum é fator fundamental do desenvolvimento. Dessa forma, as trocas entre parceiros não são só valorizadas, como também incentivadas na medida em que resultam, na experiência humana, em conhecimento co-construído com o outro. Branco e Valsiner (1997) apresentam o conceito de interação social como um processo em que todos os participantes estão constantemente estabelecendo, afirmando e modificando suas "orientações para objetivos". Essa perspectiva, portanto, considera o caráter múltiplo e dinâmico das interações sociais, preservando a abordagem sistêmica.

Vários autores discutem sobre questões fundamentais nesse processo de negociação das "orientações para objetivos" nas interações professor-professor. Passos (2001), a esse respeito, apresenta a construção de um projeto pedagógico entre um grupo de professoras que foi se constituindo como uma expressão de um trabalho de colaboração reflexiva e que tinha como ponto de partida a análise e reformulação coletivas de suas práticas pedagógicas. Nesse trabalho, a autora cita os trabalhos de Zeichner que discute sobre o componente reflexivo na formação profissional, baseado em situações práticas reais. Zeichner, conforme salienta Passos (2001), considera que a interação dos membros do grupo deve ser valorizada, pois os professores podem se apoiar mutuamente, sustentar o crescimento uns dos outros e olhar para os seus problemas compreendendo que têm uma relação com os de outros professores, com a própria estrutura da escola ou do sistema educativo. Além disso, ele indica uma tendência democrática e emancipatória em algumas decisões do professor que podem se originar de uma prática reflexiva.

Nóvoa (2001) afirma, a esse respeito, que o aprender contínuo, essencial para o professor, deve se concentrar em dois pilares: a própria pessoa do professor, como agente, e a escola, como lugar de crescimento profissional permanente. Deve colocar, portanto, a pessoa do professor, com suas singularidades e afetos, como central na reflexão educacional e pedagógica, uma vez que a formação, para ele, depende do 
trabalho de cada um. Afirma, então, que mais importante do que formar é formar-se, pois, segundo ele, todo conhecimento é autoconhecimento e toda formação é autoformação.

Ao mesmo tempo, Nóvoa (2001) considera que a escola precisa mudar institucionalmente, pois, o contexto em que exercemos nossa atividade influencia fortemente o nosso desenvolvimento pessoal e profissional. Por isso, sugere que o professor veja a escola não só como o lugar onde ele ensina, mas onde aprende. Considera que a atualização e a produção de novas práticas de ensino só surgem de uma reflexão partilhada entre os colegas, que tem lugar na escola e nasce do esforço de encontrar respostas para problemas educativos.

Aponta, então, para a necessidade de se construir no debate sobre a formação, políticas de melhoria das escolas e de definição de uma carreira docente digna e prestigiada. Caberá, assim, à escola e ao governo criar condições básicas, com infra-estrutura e incentivos à carreira. Por suas palavras,

É no espaço concreto de cada escola, em torno de problemas pedagógicos ou educativos reais, que se desenvolve a verdadeira formação. Universidades e especialistas externos são importantes no plano teórico e metodológico. Mas todo esse conhecimento só terá eficácia se o professor conseguir inseri-lo em sua dinâmica pessoal e articulá-lo com seu processo de desenvolvimento. (Nóvoa, 2001, p. 25).

Caberá ao professor, portanto, recusar o individualismo em busca de novas práticas de ensino. As identidades isoladas, construídas historicamente pelos docentes precisam ser superadas em busca de uma dimensão de grupo, que rejeite o corporativismo e afirme a existência do coletivo profissional. Para isso o professor deve se preocupar em participar nos planos de regulação do trabalho escolar, de pesquisa e de avaliação conjunta e formação continuada, para permitir a partilha de tarefas e responsabilidades. Sugere, ainda, que o professor participe de movimentos pedagógicos que reúnam profissionais de origens diversas em torno de um mesmo programa de renovação de ensino.

Para Nóvoa (2001), essas equipes de trabalho são fundamentais para estimular o debate e a reflexão. Elas que irão consolidar sistemas de ação coletiva no seio do professorado, o que exigirá a construção de uma cultura de cooperação muito maior do que adesões ou ações individuais. Dessa forma, para ele, a articulação teoria e prática só funciona se não houver divisão de tarefas e todos se sentirem responsáveis por facilitar a relação entre as aprendizagens teóricas e as vivências e observações práticas.

Nessa perspectiva, a escola deve servir como espaço de trabalho e formação, o que implica gestão democrática e práticas curriculares participativas, que propiciem a constituição de redes de formação contínua, cujo primeiro nível é a formação inicial. Essa perspectiva valoriza o trabalho do professor como sujeito das transformações que se fazem necessárias na escola e na sociedade e sugere tratamento indissociado entre formação, condições de trabalho, salário, jornada, gestão e currículo.

Tacca e Branco (2003) ressaltam o papel da comunicação nos processos interativos e trazem estudos sobre processos de significação no contexto educacional. Nesses estudos mostram que, em qualquer processo interativo, todos os envolvidos são sujeitos ativos e têm a comunicação como eixo principal do processo interativo. Esta, por sua vez, não está restrita a meios verbais e diretos, mas abrange qualquer forma que resulte em interação e conduza ao alcance de algum objetivo, ou seja, inclui o cognitivo, o afetivo e as emoções. Dessa forma, para as autoras, a qualidade da comunicação e o lugar que os sujeitos nela ocupam têm grande importância na análise dos processos interativos. Destacam, além disso, a importância de se compreender os sentidos subjetivos que integram o processo comunicativo. De acordo com essas autoras, processos comunicativos efetivos ocorrem por meio de interações capazes de atingir a estrutura motivacional dos sujeitos que dela participam. Só dessa forma, esses processos são capazes de promover o desenvolvimento dos sujeitos.

Snyders (1978), também, traz contribuições para essas questões quando discute sobre as pedagogias não-diretivas. De acordo com esse autor a contribuição da não-diretividade é a de ter situado no primeiro plano das preocupações, as relações nos grupos. Para ele todas as pessoas de um grupo têm um papel ativo a desempenhar e, por isso, é preciso que tenham direito à palavra para que possam exprimir o que sentem.

$\mathrm{O}$ autor afirma que o grupo forma uma unidade na qual devem ser estabelecidas relações confiantes, abertas e de diálogo autêntico. A cada membro do grupo cabe a responsabilidade de tomar em consideração a individualidade do companheiro, dar atenção, ser sensível às suas reações e elucidar as relações vividas no grupo, o que, para ele, não pode ser executado senão em comum. No entanto, Snyders (1978) ressalta seu receio de que este esforço para a democracia no grupo, pela não-diretividade, se afunde no conformismo e não consiga promover a vida do grupo, suas riquezas e divergências fecundas, conduzindo-o a regressar a posições puramente individuais ou a se perder na sua própria contemplação.

Nessa perspectiva, pensamos que o debate, que ocorre por meio de questionamentos, negociações, exemplificações, coloca-se como atividade obrigatória nas interações professorprofessor na escola para a promoção de uma concepção de Homem, Mundo, Sociedade e Educação, mais flexível e menos alienante. Se os professores da escola conseguem estabelecer uma atmosfera de respeito mútuo, na qual as divergências são acolhidas, visões distintas confrontadas, bases de desacordos compreendidas e soluções comuns buscadas, poder-se-á dizer que, de fato, a interação social do grupo é não só formativa como também constitutiva de um novo saber e de uma nova forma de relacionamento interpessoal.

\section{Método}

\section{A co-construção das informações}

O estudo foi realizado em um curso de formação de professores de nível médio - Curso Normal - da Rede Pública do Distrito Federal, selecionado devido aos excelentes resultados apresentados nas avaliações realizadas durante a gestão 1995-1999. O curso estava inserido em uma escola que atendia também, no período diurno, aos diferentes níveis da educação básica e, no período noturno, o ensino fundamental e médio, nas modalidades regular e supletivo, cada qual com sua equipe técnica, pedagógica e administrativa. 


\section{Participantes}

Participaram do estudo, a coordenadora pedagógica, o diretor e todos os 23 professores do Curso Normal, num total de 25 participantes. Todos eles eram professores concursados da SEE-DF e possuíam nível superior de escolarização. Desse total, 10 foram selecionados para entrevista e os demais participaram dos procedimentos de observação. O Quadro 1 apresenta os participantes entrevistados do estudo.

Quadro 1. Características dos participantes entrevistados.

\begin{tabular}{|c|c|c|c|}
\hline Participantes & $\begin{array}{c}\text { Tempo } \\
\text { de Escola }\end{array}$ & $\begin{array}{l}\text { Área de } \\
\text { Formação }\end{array}$ & Função na Escola \\
\hline P1 & 09 anos & Pedagogia & $\begin{array}{l}\text { Prof. }^{\circ} \text { de Psicologia da } \\
\text { Educação }\end{array}$ \\
\hline $\mathrm{P} 2$ & 06 anos & Pedagogia & $\begin{array}{l}\text { Prof. a de Metodologia da } \\
\text { Matemática }\end{array}$ \\
\hline P3 & 11 anos & Pedagogia & Coordenadora de Estágio \\
\hline P4 & 19 anos & $\begin{array}{l}\text { História } \\
\text { Geografia } \\
\text { Sociologia } \\
\text { Filosofia }\end{array}$ & $\begin{array}{l}\text { Prof. }^{\circ} \text { de Sociologia da } \\
\text { Educação e Filosofia da } \\
\text { Educação }\end{array}$ \\
\hline P5 & 15 anos & Matemática & Prof. o de Matemática \\
\hline P6 & 21 anos & Educação Física & $\begin{array}{l}\text { Prof. }{ }^{\circ} \text { de Metodologia da } \\
\text { Ed. Física }\end{array}$ \\
\hline P7 & 02 anos & Letras Português & Prof. ade Português \\
\hline P8 & 03 anos & Química & Prof.a de Química \\
\hline $\begin{array}{l}\text { Coordenadora } \\
\text { Pedagógica }\end{array}$ & 07 anos & $\begin{array}{l}\text { Matemática } \\
\text { Pedagogia }\end{array}$ & $\begin{array}{l}\text { Coordenação Pedagógica } \\
\text { do Curso Normal }\end{array}$ \\
\hline Diretor & 11 anos & Engenharia Civil & Direção Geral da Escola \\
\hline
\end{tabular}

Os aspectos de ordem ética - garantia de sigilo e autorização para utilização do gravador - foram rigorosamente respeitados em todas as entrevistas, sendo que todos os entrevistados assinaram o Termo de Consentimento Livre e Esclarecido².

\section{Procedimentos de construção dos dados}

A metodologia utilizada para co-construção e análise das informações foi baseada em trabalhos de natureza semelhante, tais como Branco e Madureira (2001), Maciel (1999) e Tacca (2000) e envolveu procedimentos de observação, entrevistas e análise documental ${ }^{3}$ (Raposo, 2001).

\section{Observação}

Durante os três primeiros meses letivos do ano 2000, a primeira autora deste trabalho participou, num procedimento de observação participante, das atividades que envolviam os projetos coletivos realizados pelos professores do Curso Normal

2 Estes estão redigidos segundo parecer do Ministério da Saúde e se encontram à disposição com as autoras.

3 Foi analisado o Projeto do Curso Habilitação ao Magistério (1995), que serviu como importante referencial na compreensão da história da escola, do seu projeto pedagógico e da organização do trabalho pedagógico no Curso Normal. e das reuniões pedagógicas semanais entre professores e coordenação pedagógica. As observações, sempre discutidas com a segunda autora deste trabalho, tiveram como foco a forma de relacionamento dos professores, atentando-se especialmente para os modos comunicativos e metacomunicativos como estes resolviam conflitos e chegavam aos objetivos coletivamente propostos. No total foram observados 21 encontros de professores, resultando em 82 horas, registradas em forma de anotações de campo. Dessas, oito horas foram gravadas em áudio e transcritas na íntegra.

\section{Entrevistas}

Nesse mesmo período, foram realizadas 10 entrevistas com os participantes já apresentados. A partir de um roteiro semi-estruturado, solicitava-se aos entrevistados que falassem da história da escola e de sua participação nela, especificando a história da coordenação coletiva e a forma como ela foi sendo constituída ali; como cada professor via e que importância atribuía à qualidade das interações nos processos de construção, execução e avaliação dos projetos pedagógicos desenvolvidos na escola; e, qual o papel das lideranças nas atividades propostas pelo grupo. Além disso, buscava-se explorar assuntos surgidos nas observações ou em entrevistas anteriores e que pareciam relevantes. Contudo, procurou-se deixar ao professor a organização do seu discurso, buscando-se utilizar seus próprios conteúdos para ampliá-lo e aprofundá-lo.

Após cada uma das entrevistas, era solicitado ao entrevistado um espaço aberto para re-discussão, caso, depois da análise da entrevista, surgissem dúvidas a respeito de alguma questão. No total, foram sete horas e 46 minutos de entrevistas gravadas em áudio e transcritas na íntegra.

\section{Procedimentos de análise}

As estratégias utilizadas para análise envolveram a sistematização de todo o conteúdo das observações registrado em diário de campo e em áudio, já transcrito, além do material co-construído nas entrevistas. Nesse processo de sistematização foi realizada uma leitura reiterada das anotações apresentadas no diário de campo e nas transcrições. Guiadas pelos preceitos da abordagem sociocultural construtivista, assumidamente interpretativos (Branco \& Valsiner, 1997), nessa leitura, sublinhava-se os elementos representativos para os objetivos propostos no estudo e reunia-se os trechos sublinhados em grupos que possuíam o mesmo conjunto de idéias, tendo-se em conta as seguintes questões:

- Quem define os temas discutidos nos encontros semanais dos professores e como é conduzida a discussão desses temas no sentido de atender os interesses individuais ou coletivos?

- Como são estabelecidos acordos de utilização da palavra e do tempo: todos têm oportunidades de falar?

- Como são resolvidos os conflitos de objetivos que caracterizam os processos de negociação no sentido do estabelecimento dos objetivos comuns?

- Como são distribuídas as tarefas nos momentos de execução dos projetos e quem acompanha e avalia essa distribuição e execução de atividades? 
- De que forma as atividades são avaliadas, e quem participa desse processo, e de que forma essa avaliação repercute nos projetos futuros?

- Qual o papel que cada um desempenha e como os professores, coordenação e direção reagem a essa avaliação?

\section{Resultados e Discussão}

A análise dos dados, orientada pelas idéias teóricas do sociocultural construtivismo que fundamentam o estudo e pelas questões apresentadas, conduziu à construção das seguintes categorias consideradas constitutivas das interações aqui focalizadas:

(1) Relações de confiança - interpretada a partir dos estudos de McDermott (1977), as relações de confiança são aqui entendidas como,

(...) item crucial nos acordos de trabalho feitos pelas pessoas para avaliarem-se umas às outras (...) ou seja, como eles (os pares) podem entender o comportamento um do outro, de maneira direcionada para alcançar os objetivos comuns que os mantém trabalhando juntos; e como eles podem atribuírem-se responsabilidades pela ocorrência de qualquer falha no consenso previamente formulado. (p.199)

(2) Interdependência indivíduo-grupo - a partir dos estudos de Johnson e Johnson (1992), entendeu-se a interdependência indivíduo-grupo como a percepção que os participantes de um grupo possuem da interdependência que têm entre si e que o sucesso de todos é mutuamente causado.

(3) Liderança - a liderança foi compreendida a partir dos estudos de Moscovici (1998) que propõe uma liderança compartilhada entre os diversos participantes do grupo uma vez que, segundo ela, "o complexo processo de interação humana exige de cada participante um determinado desempenho, o qual variará em função da dinâmica de sua personalidade e da dinâmica grupal na situação-momento, ou contexto-tempo.” (p. 125)

A análise e discussão dos dados, organizadas a partir dessas categorias, são agora apresentadas visando um aprofundamento teórico e conseqüente re-significação dos seus conteúdos.

\section{As relações de confiança - exemplo de co-construção}

Logo nos primeiros contatos com a escola, durante a semana pedagógica ocorrida no início daquele semestre, conforme registrado em diário de campo, observamos que o grupo possuía uma forma rápida e organizada de tomar decisões. Num breve espaço de tempo observamos e registramos sugestões serem levantadas, analisadas, definidas e defendidas. Na primeira reunião de coordenação do ano, por exemplo, enquanto elaboravam a agenda dessas coordenações para o semestre, vimos o grupo se preocupar em definir as atividades a serem desenvolvidas com detalhes, determinando os horários, fazendo um cronograma de lanches, definindo temas de estudo, etc. Essas decisões eram tomadas de forma que cada um apresentava sua sugestão que era analisada/completada minuciosamente pelos outros, considerando-se, fundamentalmente, o bem-estar do aluno e o trabalho coletivo.
Um dos aspectos observados com freqüência, tanto nas entrevistas quanto nas discussões coletivas, foi o espírito democrático com que o grupo expressava seus sentimentos e emoções em relação ao outro e o conseqüente efeito positivo dessa expressão. Vimos, por exemplo, em um encontro em que planejavam a Oficina do Jornal, uma professora desculpando-se com o grupo, pois sua participação na atividade estava inviabilizada. A professora informa ao grupo que, nos momentos em que a Oficina estivesse se desenvolvendo, ela estaria participando de um curso de língua estrangeira oferecido pela própria SEE-DF. Apesar de oficialmente respaldada, vimos o grupo se manifestar imediatamente desaprovando a atitude da colega. A referência maior da discussão era a priorização das atividades coletivas sobre as individuais para "construção de uma escola melhor a cada dia". Convencida, a professora retomou sua decisão, atendendo a necessidade da escola e do grupo.

Interpretamos essas atitudes observadas no grupo como constitutivas das relações de confiança, fundamentais para que este conseguisse alcançar os objetivos planejados.

Foi observado, naquele período, que existiam no grupo algumas regras explícitas de participação utilizadas nos momentos de tomada de decisões e nos planejamentos e execuções de atividades coletivas. Cada professor ia oferecendo suas sugestões, que eram analisadas, apoiadas ou contrapostas pelos demais colegas, chegando-se a consensos rapidamente. Existia, também, uma preocupação geral, não só da coordenação, em alertar o grupo para possíveis desvios durante as reuniões, a fim de objetivar as ações, evitando reuniões cansativas e demoradas. Dessa forma, os encontros eram produtivos, na medida em que a negociação das divergências era controlada por orientação clara para objetivos (goal orientations), que permitia o grupo encontrar rapidamente seus pontos de convergência (Branco \& Mettel, 1995). Mesmo sem haver uma combinação prévia de quem ia coordenar, registrar, fazer inscrições para as falas ou controlar o tempo, todos esses papéis eram co-construídos rapidamente e executados sem necessidade de se despender energia e tempo para decidir como fazer.

Os pontos levantados eram amplamente discutidos. As pessoas colocavam o que as incomodava e, ao mesmo tempo, ofereciam sugestões alternativas para aquela questão. Essas sugestões eram analisadas minuciosamente por todos, levantando-se pontos positivos e negativos de cada uma delas, considerando-se como prioridade maior o bem-estar do aluno e o trabalho coletivo. O mais interessante é que tudo isso era feito de forma rápida, organizada, respeitosa, aberta e democrática. Nos momentos de avaliação das atividades desenvolvidas, as regras de construção coletiva, cujos critérios básicos de funcionamento se baseavam nos objetivos da atividade avaliada em consonância com o projeto mais amplo do curso, eram relembradas. $\mathrm{O}$ grupo dialogava e chegava a consensos de forma rápida e aprazível para todos, tendo como referência maior o trabalho coletivo (goal orientations).

As pessoas em geral estavam abertas à negociação e a, em qualquer momento, abrir espaço de discussão sobre temas que estivessem em questão. Nas entrevistas, muitos professores se manifestaram afirmando a importância dessa liberdade para expressar seus sentimentos, valores, opiniões e emoções no grupo. A esse respeito, P1 afirma acreditar que o que faz 
com que o grupo "alcance esse bom nível interativo seja um objetivo comum de construir uma escola melhor a cada dia". Ela acredita ainda que através dos encontros de coordenação pedagógica foi se "estabelecendo uma relação entre os professores onde eles têm oportunidades de se conhecerem mutuamente, avaliarem-se e fazer com que as diferenças se tornassem motivo de encontros e sintonias". Afirma que não deixam de dizer o que pensam e que crescem com isso:

\begin{abstract}
"A gente ganha pouco, passa o dia aqui dentro, tem todo um idealismo em termos de Educação e se não tivermos a transparência de questionar o colega por ele ter feito algo individual ou por ele não ter respeitado a opinião do coletivo, como é que a gente vai crescer? Como é que aquele colega vai crescer? De repente ele pensa que está abafando e se a gente não disser que é um equívoco aquilo que ele está fazendo, como é que ele vai perceber isso? Ou como é que eu poderei ver diferente? Então a gente diz. Se não gostou fica uns dias de cara virada e depois a gente se retrata, a gente se desculpa, lava a roupa suja, mas crescemos para o próximo planejamento juntos." (professora P1)
\end{abstract}

A Coordenadora, por sua vez, acredita que o hábito de se camuflar sentimentos conduz a um freio no processo de construção coletiva que precisa ser superado através de exaustivos diálogos abertos. Para ela, o maior problema de uma relação em grupo é a omissão de informações por parte de alguém do grupo. Ela diz: "Eu preciso estar bem comigo mesmo, com meu colega e com meu trabalho". Além disso, entende que: "estar bem comigo mesmo exige espaço para que se possa colocar para o outro a sua indignação" e que, embora "sejam amigos e tenham uma relação próxima, existe muita cobrança tanto da parte da coordenadora para o grupo como vice-versa ou entre o próprio grupo".

McDermott (1977) ao estudar os fundamentos relacionais de uma pedagogia bem sucedida, define relações como "acordos de trabalho ou consenso sobre quem eles são (as pessoas em interação) e o que acontece entre eles, acordos que eles formulam, agem sobre, e usam juntos para avaliarem-se uns aos outros." (p. 199). Além disso, McDermott entende confiança como uma qualidade de relacionamento entre pessoas, produto do trabalho a que se propõem para alcançar objetivos comuns e alcançada por meio das interações.

A tese defendida pelo autor, muito útil na nossa discussão, é que, em contextos em que se oferecem aos professores recursos suficientes para trabalharem juntos no estabelecimento de um ambiente de confiança, eles terão tempo e energia suficientes para se dedicarem às tarefas que lhes são atribuídas. Acredita, também, que o sucesso na organização dessas tarefas depende de quão bem sucedidos são os participantes em comunicar ao outro a importância das mesmas.

Pudemos observar que essa tese era vivenciada intensamente nesse grupo. Este reconhecia o contexto relacional como um espaço de trocas constantes no qual suas idéias, experiências, construções privilegiadas, preconceitos e ilusões eram trazidos para o processo no qual também a sua versão da realidade é passível de mudança. Nesse modelo de relação, a negociação e co-construção de significados, valores e conhecimentos eram o grande desafio do grupo. Dessa forma, historicamente foram construindo as relações de confiança necessárias para que pudessem superar esse desafio e re-elaborar ou redescobrir o seu lugar naquelas relações.

\section{A interdependência indivíduo-grupo: a busca do coletivo e o respeito à individualidade}

Outro aspecto relevante observado no grupo em questão foi a interdependência do indivíduo em relação ao grupo e vice-versa. Nos núcleos, a rotina diária oferecia uma estrutura de funcionamento que estimulava a experiência social - os professores eram continuamente desafiados à reflexão e ao debate. Nessas reuniões, os professores faziam avaliações, festejavam sucessos, dividiam angústias, reviam diagnósticos e articulavam-se na construção de objetivos, num tom de franqueza, cooperação, confiança e respeito. Havia espaço, por exemplo, para o professor apresentar seu plano de atividades semanal ou mensal para o grupo e ouvir o que cada uma das outras áreas podia trazer para enriquecer ou aprender com a sua experiência.

A relação coordenadora-professores e professoresprofessores, pareceu-nos servir de grande suporte na organização do trabalho pedagógico do professor em sala de aula, uma vez que, ao mesmo tempo em que o professor percebia a importância das contribuições do grupo na organização do seu trabalho pedagógico, sentia-se completamente responsável na organização do trabalho de seus colegas, uma vez que estava, também, oferecendo inúmeras contribuições sistemáticas.

Nas entrevistas, os professores se manifestaram em relação a essa questão de diferentes formas. A professora P8, por exemplo, acredita que "o grupo é fundamental para o crescimento de cada um". Para ela, através dos encontros semanais, o professor passa a conhecer o colega, seu trabalho profissional, seu envolvimento ético e, por consequiência, passa a ajudá-lo e a receber a sua ajuda, tornando-se co-responsáveis entre si. A professora P2 expressa sua concordância a esse respeito quando afirma que "Ninguém sabe tudo, a gente está sempre aprendendo com o outro". De acordo com ela, o trabalho coletivo oferece ao professor uma visão maior do processo, abrindo novos horizontes para a organização do trabalho pedagógico de sua sala de aula.

$\mathrm{Na}$ entrevista com a professora P7, ficou marcada a idéia de que o trabalho individual pode produzir resultados maravilhosos. Entretanto, segundo ela, "esses resultados são limitados em relação ao que se pode produzir quando se envolve o coletivo como um todo". No entanto, considera imprescindível que "os objetivos dessa atividade devam, de alguma forma, atender os objetivos individuais de cada um". A professora P1 entende que, talvez, o que faz com que o grupo alcance esse bom nível interativo seja o objetivo comum de construir uma escola melhor a cada dia. Entende que "o papel da coordenadora pedagógica tem sido fundamental para essa boa interação", mas não consegue definir se o grupo é assim "por que o coordenador ajuda ou se o coordenador ajuda por que o grupo é assim". O professor P5, a esse respeito, afirma:" $E$ assim... trabalhou-se o individual para se chegar ao coletivo e trabalhou-se o coletivo para chegar ao individual".

Johnson e Johnson (1992) discutem essa questão, afirmando que para se alcançar uma cooperação efetiva é 
necessário, entre outras coisas, considerar o grau em que os participantes percebem que são interdependentes entre si e que o sucesso dessas interações é mutuamente causado. De acordo com esses autores, cooperar é trabalhar junto para alcançar objetivos comuns. Nessas situações, os objetivos dos participantes são positivamente correlacionados, ou seja, o indivíduo percebe que ele só pode alcançar seu objetivo se também for objetivo dos outros membros do grupo. Assim, ele procura objetivos que sejam benéficos a todos.

Esses autores entendem que a interdependência social possui três características que se relacionam entre si de forma multidirecional: esforço exercido para alcançar êxito, qualidade de relacionamento entre os participantes e competência social e ajustamento psicológico entre os participantes. Essas dimensões da interdependência social tendem a ser encontradas juntas e cada uma contribui para a presença da outra. Para eles,

Em situações cooperativas a interdependência positiva é estruturada para criar um padrão de interação fomentador (o que requer habilidades sociais) no qual se pode perceber o esforço dos participantes para alcançar êxito, a qualidade do relacionamento entre os participantes e o ajustamento psicológico dos mesmos, o que não se percebe em situações de competição ou individualísticas. (Johnson \& Johnson, 1992, p. 176)

Enfim, nos vários momentos desse estudo - observaçãoparticipação, entrevista e análise das informações - ficou claro para nós que o grupo se sentia co-responsável pelos resultados dos trabalhos, tanto individuais como coletivos, daquela escola, bem como essa co-responsabilidade propiciava o alcance dos objetivos que eram individual e coletivamente propostos.

\section{A liderança no grupo - o compartilhamento}

A questão da liderança era muito discutida no grupo, enfocada como elemento fundamental para o alcance dos objetivos individuais e coletivamente propostos (goal orientation). No processo de co-construção das informações nessa escola pudemos perceber que o eixo central da gestão do seu projeto político-pedagógico eram as reuniões semanais dos professores, nomeadas reuniões de núcleos disciplinares, que possuíam como linha básica de ação o trabalho coletivo. Esse trabalho parecia se configurar como uma possibilidade de resgatar a unidade do trabalho do professor, possibilitando aos educadores a decisão e a concepção de seu trabalho conjugada à execução, através dos núcleos, além de propiciar aos professores a visão global do trabalho de sua área do conhecimento e das demais que compunham o curso. No trabalho de gestão desenvolvido na escola, a tarefa essencial era oferecer ao professor a possibilidade de conhecer, de apropriar-se, de transformar o processo de produção dentro da escola.

$\mathrm{Na}$ entrevista com a coordenadora, ela afirmou que:

"Para mim o trabalho coletivo começa assim: eu produzo com
um grupo pequeno respeitando a identidade daquele pequeno
grupo, respeitando seus posicionamentos e vendo as divergên-
cias. Quando nós temos um posicionamento em cada um desses
pequenos grupos reunimos todos para tirarmos as diferenças e decidirmos como nós vamos trabalhar. Tomando as decisões coletivamente, todos se sentem respeitados em sua individualidade, e sentem que podem participar. Se o professor sente que a sua vontade valeu, ele busca colaborar sempre."

Segundo a coordenadora, essa é uma tarefa muito difícil, uma vez que "depende de muita negociação, além de um conhecimento profundo do grupo e um acompanhamento sistemático de tudo que está acontecendo na escola". Para a professora P1, a coordenadora é uma "espécie de super-homem, que ouve as angústias e sonhos do professor e negocia esses ideais com a direção e com as outras modalidades da escola". O trabalho do líder para ela, portanto, é "interpretar o que o grupo quer e favorecer situações para que as coisas aconteçam.” De acordo com a coordenadora, a estratégia para desenvolvimento desse trabalho coletivo na escola passou pelos seguintes passos:

\footnotetext{
"Eu comecei a dar liberdade para o professor. Acho que o professor precisa disso, de liberdade para saber que pode criar.. então eu disse a eles: vocês vão criar no horário de projeto aquilo que vocês acham que não podem fazer em sala. Podem planejar o que querem, realizar o sonho de vocês... eu estarei aqui para ajudar vocês."
}

A abordagem sociocultural construtivista retrata a questão da liderança quando entende a escola enquanto um sistema social em permanente processo de construção, no qual as organizações se transformam pelas interações entre os diversos atores sociais que, subjetivamente, selecionam de sua realidade objetiva os elementos significativos que influenciarão o seu comportamento, dando ao seu papel conteúdo específico, do ponto de vista do sujeito, e diferenciado, do ponto de vista social.

Portanto, a reorganização social resulta da contraposição das diferentes percepções individuais sobre os problemas organizacionais geradas pela liberdade e criatividade humana. Desse modo, o indivíduo livre e criativo pauta seu comportamento na racionalidade substantiva, derivada de sua própria razão, rejeitando a condição de ser passivo, submetido à obediência cega, às exigências de eficiência ditadas pela racionalidade funcional. Essa crença na liberdade e criatividade do homem desloca o foco de poder nas organizações, pressupondo um modelo de gestão participativo, cuja liderança é centrada na visão de globalidade, na mobilização de recursos e na construção de arranjos institucionais para a concretização dos objetivos da organização e de seus membros e enfatiza a capacidade de negociação e de partilhamento de poder.

Essa capacidade de direção para o exercício da liderança requer do líder, a condição de educador comprometido com os valores democráticos dos novos tempos. Assim, cabe a ele assegurar as condições de liberdade para que as pessoas possam desenvolver uma visão crítica e fazer as escolhas adequadas, tornando significativas as atividades organizacionais para aqueles que executam.

Nessa discussão fica explícita a compreensão comum de liderança como o articulador entre os diversos componentes do grupo de forma que cada um tenha a oportunidade de demonstrar suas competências e apresentar suas contribuições através de uma liderança compartilhada. Desta 
forma, em diferentes momentos na organização dos trabalhos, uma ou outra pessoa podia assumir a responsabilidade pela liderança das atividades, de acordo com sua especificidade e as competências necessárias para aquela atividade. A professora P1 reconhece essa idéia na escola e a expressa quando afirma que "sempre tem um de nós que puxa o grupo fazendo com que se abram as discussões".

Moscovici (1998), sobre essa questão, afirma que é usual e enganoso pensar os membros do grupo desempenhando apenas duas funções distintas: liderança e participação simplesmente. Para ela a liderança não pode ser tão marcada e continuamente desempenhada por apenas um membro do grupo. Outros membros assumem liderança informal, de acordo com as diferentes situações por que passa o grupo em seus processos de interação. Além disso, a função do membro do grupo, usualmente identificado como não-líder, poderia dar a impressão de um comportamento não-diferenciado, comum a todos os componentes do grupo, excluído o líder que tem um papel nitidamente caracterizado.

A autora referida entende que a vida do grupo passa por várias fases e que os membros do grupo atuam de forma diferenciada em cada uma delas em relação tanto à etapa de vida do grupo como em relação aos demais membros. A esse respeito, em sua entrevista a coordenadora sintetiza o trabalho desempenhado pela coordenação da seguinte forma:

\begin{abstract}
"Eu faço uma analogia da coordenação de um trabalho coletivo com a confecção de um bolo. Quando estamos fazendo a massa de um bolo, nas bordas da vasilha, fica sempre ressecada, encostada, alguma coisa que se você não pegar com uma espátula e trouxer para dentro da massa, aquela coisa vai se perder lá, vai ficar dura e não vai fazer parte da massa. O trabalho de coordenação é justamente esse, estar trazendo as pessoas para participar e sentir-se parte do grupo.”
\end{abstract}

A experiência da escola em estudo nos aponta elementos importantes que evidenciam um significativo exercício de liderança e organicidade no interior da escola. O trabalho voluntário e comprometido apresenta reflexões importantes que o retira do nível do senso comum. A consciência presente na escola de que sua função social supera os limites da erudição, do psicologismo e do tecnicismo da pedagogia liberal para assumir uma dimensão política, comprometida com a liberdade, a autonomia, a coletividade, a democracia, o engajamento e a formação para a cidadania.

\section{Considerações Finais}

O exercício de análise realizado neste trabalho aponta para elementos presentes no processo interativo dos professores que facilitam o alcance dos objetivos individuais e coletivamente propostos e que são fundamentais para a co-construção do projeto político-pedagógico vivido pela escola. A análise do processo das interações do grupo estudado foi realizado a partir de três categorias, elaboradas a partir do referencial teórico e da própria leitura dos dados de observação e entrevista: (1) relações de confiança; (2) interdependência indivíduo-grupo e (3) liderança. Estas expressam um momento de construção desse grupo de professores e o contexto histórico onde esse aparece como significativo.
A explicitação dos processos interativos sistematizados e analisados a partir dessas categorias são compreendidas por nós como uma contribuição relevante desse estudo para os cursos de formação inicial e continuada de professores. Tal análise poderá servir como tema de reflexão para os projetos pedagógicos das escolas, para os professores e futuros professores, para as equipes de direção e todos que estiverem vinculados à formação de professores, de uma forma ou outra. Ao estudar as interações interpessoais percebemos que simplesmente colocar indivíduos em grupo e dizer então para trabalharem juntos, não promove, por si só, o sucesso no alcance dos objetivos. Existem muitas formas nas quais os esforços do grupo podem dar errado. Somente sob certas condições esses esforços podem ser mais produtivos que esforços individuais. Consideramos que as categorias desse estudo poderão servir como referência nessa discussão.

\section{Referências}

Branco, A. U. (1998). Cooperation, competition and related issues: A co-constructive approach. Em M.C. Lyra \& J. Valsiner. (Orgs), Child development within culturally structured environments, 4, Construction of psychological processes in interpersonal communication (pp. 181-205). Norwood: Ablex Publishing Corporation.

Branco, A. U. \& Madureira, A. F. (2001). Pesquisa qualitativa em psicologia do desenvolvimento: questões epistemológicas e implicações metodológicas. Temas de Psicologia, 9(1), 63-75.

Branco, A. U. \& Mettel, T. P. L. (1995). Canalização cultural das interações criança-criança na pré-escola. Psicologia: Teoria e pesquisa, 11(1) 13-22.

Branco, A. U. \& Valsiner, J. (1994, julho). Co-constructivist perspectives on the coordination of goal orientation in social interaction. Trabalho apresentado em Simpósio do $23^{\circ}$ Congresso Internacional de Psicologia Aplicada, Madri, Espanha.

Branco, A.U. \& Valsiner, J. (1997) Changing methodologies: a co-construtivist study of goal orientations in social interactions. Psychology and Development Societies, 9(1), 35-64.

Governo do Distrito Federal, Secretaria de Educação e Fundação Educacional do Distrito Federal (1995). Projeto do Curso Habilitação ao Magistério. Brasília.

Johnson, D. W. \& Johnson R. T. (1992). Positive Interdependence: Key to effective cooperation, Em R. Hert-Lazarowitz. \& N. Miller (Orgs.), Interaction in cooperative groups: the theoretical anatomy of groups learning (pp. 174-199). Cambridge University Press.

Maciel, D. A. (1996). Análise das interações professora-criança em situações de ensino-aprendizagem da leitura e escrita. Tese de doutorado, Universidade de São Paulo, São Paulo.

Maciel, D. A. (1999). A co-construção da subjetividade no processo de aquisição da leitura e escrita. Em M. G. Torres da Paz \& a Tamayo. (Orgs.), Escola, Trabalho e Saúde: Estudos Psicológicos (pp. 41-70). Brasília: EDUnB.

Maciel, D., Branco, A. U. \& Valsiner, J. (2004). Bidirectional processes of knowledge construction in teacher-student transaction. Em A. U. Branco \& J.Valsiner (Orgs.), Communication and metacommunication in human development (p. 109-125), Greenwich: Information Age Publishing Co. 
McDermott, R. P. (1977). Social Relations as Contexts for Learning in School. Harvard Educational Review, 47(2), 198-212.

Moscovici, F. (1998). Desenvolvimento interpessoal: treinamento em grupo. Rio de Janeiro: José Olympio Editora.

Nóvoa, A. (2001). Professor se forma na escola. Nova escola, 142. Maio.

Passos, L. F. (2001). O projeto pedagógico e as práticas diferenciadas: o sentido da troca e da colaboração. Em M. André (Org.), Pedagogia das diferenças na sala de aula (pp.107-131). Campinas: Papirus.

Piaget, J. (1966). La naissance de línteligence chez lénfant. Suíça: Dalachaux et Niestlé.

Raposo, M. (2001). A Interação professor-professor no contexto de uma escola pública do Distrito Federal. Dissertação de Mestrado, Universidade de Brasília, Brasília.

Salomão, S. (2001). A co-construção de crenças e valores: comunicação e metacomunicação nas interações professoraalunos em sala de aula. Dissertação de Mestrado, Universidade de Brasília, Brasília.

Snyders, G. (1978). Para onde vão as pedagogias não-diretivas? Lisboa: Moraes Editores.
Tacca, M. C. (2000). Ensinar e aprender: análise de processos de significação na relação professor-aluno em contextos estruturados. Tese de Doutorado, Universidade de Brasília, Brasília.

Tacca, M. C. \& Branco, A. U. (2003). Comunicación y metacomunicación en situaciones de enseñanza y aprendizaje. Revista de Psicología, 7(2), 127-145.

Valsiner, J. (1997). Crossroads of the deductive and inductive lines of knowledge construction in psychology. Em J. Valsiner (Org.), Quais autores do livro Culture and the development of children's actions. $2^{\mathrm{a}}$ Ed. (pp. 67-125). New York: Wiley. (Trabalho original publicado em 1987)

Wallon, H. (1971). As origens do caráter da criança. São Paulo: Difusão Européia do Livro.

Recebido em 23.03.2005

Primeira decisão editorial em 12.07.2005

Versão final em 16.09.2005

Aceito em 14.10.2005

\section{MUDANÇA DE ENDEREÇO}

Se você está mudando de endereço, por favor, notifique Psicologia: Teoria e Pesquisa. Ocasionalmente, assinantes e autores comunicam tardiamente mudança de endereço gerando dificuldades na entrega de nossa revista ou de outras correspondências. Informe imediatamente, se possível com antecedência, qualquer mudança de domicílio para:

Universidade de Brasília - Instituto de Psicologia

Revista Psicologia: Teoria e Pesquisa

Secretaria de Divulgação

70910-900 Brasília DF

Mudanças de endereço poderão também ser comunicadas através do correio eletrônico revptp@unb.br ou do telefone e fax 556132746455 . 